\title{
HEART SCORE SEBAGAI ASSESMENT PADA PASIEN DENGAN CHEST PAIN DI INSTALASI GAWAT DARURAT
}

\author{
Mus'ab Ridho Syafii ${ }^{1, *}$, Beti Kristinawati ${ }^{2}$ \\ ${ }^{1,2}$ Universitas Muhammadiyah Surakarta \\ ${ }^{1}$ musab.xo633@gmail.com*
}

\begin{abstract}
Abstrak
Latar Belakang : Pasien yang mengalami nyeri dada sebagai indikasi syndrome koroner akut umumnya memiliki ciri khas, tetapi terkadang terdapat keluhan nyeri dada unspecific. Heart score merupakan alat pengkajian untuk mengidentifikasi pasien berdasarkan klasifikasi resiko rendah, resiko menengah, dan resiko tinggi.

Tujuan : Evidence Based Nursing bertujuan untuk mengetahui efektivitas penggunaan heart score pada pasien dengan chest pain di Instalasi Gawat Darurat.

Metode : Pencarian literature digunakan untuk menyusun matrix jurnal yang akan diterapkan sesuai topik Heart score sebagai tools pengkajian pada pasien dengan chest pain. Intervensi assessment dilakukan pada pasien yang datang ke IGD RSUD Ir. Soekarno Sukoharjo. Sampel diambil menggunakan metode purposive sampling, kemudian hasil diinterpretasikan klasifikasi skor.

Hasil : Hasil menunjukkan 2 pasien (25\%) diklasifikasikan skor 0-3 dengan resiko rendah. Terdapat 5 pasien (62.5.\%) diklasifikasikan skor 4-6 dengan resiko sedang. Sedangkan pada 1 pasien $(12.5 \%)$ dengan resiko tinggi, pasien langsung mendapatkan perawatan intensive dan dikonsultasikan ke bagian kardiologi.

Simpulan: Penggunaan Heart score memberikan manfaat dalam membantu mengklasifikasikan pasien berdasarkan resiko sehingga dapat membantu keputusan klinis yang tepat sesuai indikasi.
\end{abstract}

Kata kunci: Heart Score; Chest Pain; Instalasi Gawat Darurat

\section{HEART SCORE USE TO ASSESMENTS PATIENTS WITH CHEST PAIN IN EMERGENCY DEPARTMENT}

\begin{abstract}
Background: Patients who experience chest pain as an indication of acute coronary syndrome generally have a characteristic, but sometimes there are complaints of unspecific chest pain. Heart score is an assessment tool to identify patients based on the classification of low risk, medium risk and high risk.

Objective: Evidence Based Nursing aims to determine the effectiveness of using heart scores in patients with chest pain in the Emergency Department.

Method: Literature search is used to compile a journal matrix that will be applied according to the topic Heart score as an assessment tool in patients with chest pain. Assessment intervention was carried out on patients who came to IGD RSUD Ir. Soekarno Sukoharjo. Samples were taken using a purposive sampling method, then the results were interpreted as a score classification.
\end{abstract}

Results: The results showed 2 patients $(25 \%)$ were classified with a score of $0-3$ with low risk. There were 5 patients $(62.5 . \%)$ Classified with a score of 4-6 with 
moderate risk. Whereas in 1 patient (12.5\%) with high risk, the patient immediately received intensive care and was consulted to the cardiology department.

Conclusion: The use of Heart score provides benefits in helping to classify patients based on risk so that it can help correct clinical decisions as indicated.

Keywords: Heart Score; Chest Pain; Emergency Deparment

\section{PENDAHULUAN}

Sindrome koroner akut merupakan gejala klinis yang mengacu pada spectrum jantung dari kondisi dengan keadaan iskemia pada miokardium jantung sebagai akibat dari kurangnya aliran yang ditandai dengan nyeri dada, perubahan segmen ST pada electrocardiogram (EKG), dan perubahan biomarker jantung (AHA, 2014). Sindrome koroner akut menyebabkan nekrosis pada miokardium, sehingga suplai darah tidak adekuat yang akan menjadi infark, tanda klinis ini dapat berkembang menjadi infark miokard akut (Perki, 2018). Menurut laporan WHO, pada tahun pada tahun 2016, penyakit jantung merupakan penyebab kematian utama didunia terhitung sebanyak $31 \%$ dari total kematian yang ada didunia atau setara 17,9 juta rang dilaporkan meninggal (WHO, 2018). Sedangkan di Indonesia sendiri angka kematian dari penyakit jantung menduduki peringkat nomer satu angka mortalitas kematian yaitu sebesar 35\% dari total kematian. Kementrian Indonesia merilis laporan Riskesdas pada tahun 2018, bahwa prevalensi penyakit jantung berdasarkan diagnosis dokter pada penduduk semua umur sebanyak 1.017.290 jiwa (Kemenkes, 2018).

Pasien dengan penyakit jantung dapat tiba-tiba mengalami keluhan nyeri dada yang umunya memiliki ciri khas, antara lain dapat berupa nyeri dada yang tipikal (angina tipikal) atau angina atipikal. Keluhan angina tipikal ditandai dengan keluhan seperti rasa tertekan/berat daerah retrosternal, menjalar ke lengan kiri, leher, rahang, area interskapular, bahu, atau epigastrium. Keluhan angina tipikal dapat berlangsung selama beberapa menit maupun lebih dari 20 menit. Keluhan lain juga menyertai angina tipikal seperti diaphoresis (keringat dingin), mual, muntah, nyeri abdominal, sesak nafas, dan sinkop. Keluhan atipikal antara lain seperti nyeri dada pada daerah yang sama dengan tipikal, gangguan pencernaan (digesti), sesak nafas yang susah diungkapkan pasien, dan rasa lemah mendadak yang susah diuraikan (Perki, 2018).

Pasien yang datang di Instalasi Gawat Darurat dengan dicurigasi ACS harus segera diidentifikasi karena dapat mengancam jiwa. Diagnosis ditegakkan apabila anamnesis dapat diperoleh keluhan khas nyeri dada ACS. Hasil anamnesis dapat diperkuat dengan ditemukannya keluhan tersebut pasien dengan karakteristik lakilaki, memilik aterosklerosis, memiliki penyakit jantung koroner dengan pernah mengalami imfark miokard, pembedahan vaskularisasi jantung, serta memiliki banyak faktor resiko. Pemeriksaan fisik dilakukan untuk mengetahui faktor pencetus iskemia, komplikasi, penyakit penyerta, dan menyingkirkan bias karena diagnose banding. Pemeriksaan fisik yang ditemukan antara lain regurgitasi katup mitral akut, suara jantung tiga (S3), ronkhi basah halus, dan diaphoresis merupakan tanda kecurigaan terhadap ACS. Kakuatan nadi tidak seimbang, 
regurgitasi katup aorta akibat diseksi aorta, pneumothoraks, nyeri pleuritik disertai suara napas yang tidak seimbang perlu dipertimbangkan dalam diagnose banding ACS (Perki, 2018).

Pemeriksaan elektrokardiogram dilakukan sesegera mengkin setelah sampai diruang gawat darurat. Gambaran EKG yang dijumpai pasien dengan keluhan nyeri dada cukup bervariasi, yaitu normal, non-diagnostik, left bundle branch blok (LBBB), elevasi segmen ST, depresi segmen ST dengan inverse gelomban ST. Pemeriksaan biomarka jantung seperti kreatinin kinase-MB (CK-MB) atau troponin I/T merupakan bimarka nekrosis miosis jantung dan menjadi biomarka untuk penegakan diagnosis (Perki, 2018)

Kesulitan dalam mengidentifikasi pasien umumnya terletak pada tanda gejala nyeri yang tidak spesifik, akan tetapi juga disertai gejala seperti rasa tidak nyaman, rasa tertekan, dan diremas. Keterlambatan identifikasi pasien berpotensi menyebabkan kemungkinan hasil klinis yang merugikan pada pasien. Oleh karena itu, penentuan penilaian resiko pada awal sangat penting untuk memandu dalam manajemen pasien, melakukan pemeriksaan diagnostik tambahan serta perawatan pasien (Amsterdam, 2014).

Heart score merupakan alat pengkajian awal yang bertujuan mengidentifikasi resiko pada nyeri dada. Heart score mengidentifikasi pasien yang digolongkan berdasarkan resiko rendah, resiko menengah atau sedang, dan resiko tinggi (Brady, 2018). Heart score menilai lima komponen, yaitu history (riwayat), electrocardiogram (gambaran EKG), age (usia), risk factors (faktor resiko), dan troponin (Dai, 2018). Heart score dirancang untuk digunakan sebagai tools pengkajian pasien dengan nyeri dada yang datang di Instalasi Gawat Darurat (Six, 2013). Oleh karena itu, dengan penerapan Heart score sebagai alat pengkajian pasien yang datang dengan nyeri dada akan dapat membantu mengidentifikasi serta cukup berguna sebagai tambahan dalam pengambilan keputusan klini.

\section{METODE}

Pencarian literature digunakan untuk menyusun matrix jurnal yang akan diterapkan sesuai topik. Tools Hearts score dilakukan untuk mengkaji pasien dengan chest pain. Intervensi tool Heart score dilakukan pada pasien yang datang ke Instalasi Gawat Darurat RSUD Ir. Soekarno Sukoharjo. Sampel diambil menggunakan metode purposive sampling yang telah dipilih berdasarkan kriteria. Kriteria inklusi adalah pasien yang datang ke IGD dengan chest pain. Sedangkan kriteria eksklusinya yaitu pasien yang sudah terdiagnosa ACS, pasien yang mengalami syncope, pasien dengan palpitasi yang tampak sangat kelelahan, dan pasien trauma dada. Inform consent diberikan kepada keluarga sebagai persetujuan dilakukannya assesment tools. Pelaksanaan dilakukan dengan melakukan assessment sesuai komponen Heart score dengan memberi ceklist pada tabel yang telah tersedia pada Heart score. Kemudian hasil di interpretasikan berdasarkan nilai total skor yang digolongkan skor 0-3 (resiko rendah, pasien dapat dilakukan rawat jalan), skor 4-6 (resiko sedang, pasien diobservasi dan dilakukan evaluasi lebih lanjut), skor 7-10 (resiko tinggi, pasien mendapatkan intervensi darurat dan konsultasi kardiologi). 
HASIL DAN PEMBAHASAN

Tabel 1. Distribusi Frekwensi Karakteristik Responden

\begin{tabular}{ccccc}
\hline No & Variabel & Item & Jumlah & \% \\
\hline 1 & Jenis kelamin & Perempuan & 7 & $87.5 \%$ \\
& & Laki-laki & 1 & $12.5 \%$ \\
2 & Usia & $\leq 45$ tahun & 0 & $0 \%$ \\
& & $45-65$ tahun & 5 & $62.5 \%$ \\
& & $\geq 65$ tahun & 3 & $37.5 \%$ \\
3 & Hipertensi & Ya & 8 & $100 \%$ \\
& & Tidak & 0 & $0 \%$ \\
4 & DM & Ya & 2 & $25 \%$ \\
& & Tidak & 6 & $75 \%$ \\
\hline
\end{tabular}

Telah dilaksanakan intervensi tool Heart score dari tanggal 2 Desember hingga 16 Desember 2019 terhadap pasien yang datang dengan nyeri dada di IGD RSUD Ir. Soekarno Sukoharjo. Didapatkan subjek sebagian besar berjenis kelamin perempuan (87.5\%), seperti terlihat pada Tabel 1. Hal ini berbeda dengan hasil penelitian dinegara Timur Tengah, dimana prevalensi angka sindrom koroner akut perbandingan jenis kelamin lai-laki dengan perempuan sebesar 49 banding 46, akan tetapi disini berbanding tipis mengingat ada factor tersendiri yang mempengaruhi gender perempuan (Khesroh, 2017). Secara biologis vaskuler pada wanita memiliki perbedaan dari laki-laki, wanita memiliki diameter pembuluh koroner yang lebih kecil, aliran kolateral vaskuler yang lebih sedikit dan juga peningkatan kekakuan arteri. Pada wanita juga lebih sering terjadi adanya gangguan vasomotor koroner dalam bentuk disfungsi pada bagian epikardial dan mikrovaskuler (Tomaszewski, 2019).

Pada Tabel 1 juga menunjukkan distribusi subjek menurut usia. Pada pasien dengan nyeri dada usia $45-65$ tahun $(62.5 \%)$ dan diatas 65 tahun (37.5\%) laki-laki dan perempuan, bila disimpulkan maka mayoritas perempuan berusia diatas umur menopause yang mengalami pascamenopause. Pneyakit syndrome koroner akut pada wanita dipengaruhi oleh peningkatan tekanan kapiler paru, peningkatan tekanan pada pengisian ventrikel kiri, nilai body mass index lebih dari 30. Faktor pada wanita yang sudah mengalami menopause disebabkan oleh penurunan hormone estrogen dan progesterone. Sehingga menyebabkan obnormalitas gambaran stress yang menyebabkan kekakuan pada dinding pembuluh darah (Graham, 2016).

Pada Tabel 1 riwayat penyakit yang diderita oleh pasien adalah hipertensi (100\%). Hal ini sesuai dengan penelitian yang dilakukan di IGD RS Emam Reza, Mashad, Iran, bahwa mayoritas pasien yang datang dengan keluhan nyeri dada mamiliki penyakit hipertensi (56\%) (Bolvardi, 2016). Pada hipertensi terjadi peningkatan arteri yang menyebabkan kekakuan pada dinding pembuluh darah, menyebabkan infark miokard bersamaan dengan proses rupturnya plak dan factor resiko lainnya (Pramadiaz, 2014). Sedangkan ada 2 pasien yang memiliki riwayat diabetes mellitus (25\%), penelitian yang dilakukan di Rumah Sakit di China dari bulan November 2017 hingga Juli 2017 bahwa prevalensi pasien diabetes mellitus (29.7\%) memiliki resiko kematian dini serta beresiko mengalami sindrom koroner akut hingga akut miokard infark (Zhou, 2018). 
Tabel 2. Hasil Assesment Heart Score

\begin{tabular}{ccc}
\hline Interpretasi & n & \% \\
\hline Skor 0-3: Resiko rendah & 2 & $25 \%$ \\
Skor 4-6: Resiko sedang & 5 & $62.50 \%$ \\
Skor 7-10: Resiko tinggi & 1 & $12.50 \%$ \\
Total & 8 & $100 \%$ \\
\hline
\end{tabular}

Berdasarkan Tabel 2 hasil pelaksanaan intervensi tools Heart score yang telah dilakukan pada pengkajian awal pasien dengan nyeri dada yang datang ke IGD menunjukkan 2 pasien (25\%) diklasifikasikan skor 0-3 dengan resiko rendah, pentalaksanaan pasien yang beresiko rendah cukup hanya perawatan dirumah. Terdapat 5 pasien (62.5.\%) diklasifikasikan skor 4-6 dengan resiko sedang, maka tatalaksana yang dilakukan adalah pasien membutuhkan rawat inap dengan observasi dan dilakukan evaluasi lebih lanjut. Sedangkan pada 1 pasien (12.5\%) dengan resiko tinggi, pasien langsung mendapatkan perawatan intensive dan dikonsultasikan lebih lanjut ke bagian kardiologi.

Hasil pelaksanaan tool Heart score ini mendukung penelitian yang dilakukan oleh Ehsan (2016) yang menunjukkan bahwa paling banyak pasien yang datang dengan nyeri dada masuk kedalam kategori resiko sedang (48\%) dan memiliki peluang sebesar $14.58 \%$ untuk terkena penyakit akut miokard infark. Sedangkan pasien dengan skor resiko rendah (11\%) memiliki peluang $0 \%$ beresiko terkena akut miokard infark, lalu skor resiko tinggi (12.5\%) memiliki peluang yang lebih besar untuk terkena penyakit akut miokard infark sebesar $41.46 \%$.

Heart score dirancang untuk membantu tenaga medis dalam mengidentifikasi pasien dengan nyeri dada khas mengarah ACS atau nyeri akut yang tidak terperinci di IGD. Heart score juga membantu mengidentifikasi pasien yang beresiko rendah sehingga tidak membutuhkan tes jantung yang lebih lanjut(Brady, 2018).

Penggunan Heart score pada pasien yang diklaifikasikan resiko sedang terbukti membantu dalam efisiensi biaya pemeriksaan sebesar $85 \%$. Keuntungan yang lain, Heart score dapat meminimalkan pemeriksaan pencitraan jantung dan dapat mengurangi potensi bahaya radiasi diagnostic (Hiestand, 2012).

Heart score membantu tenaga kesehatan dalam membuat keputusan klinis yang akurat diruang gawat darurat tanpa menggunakan radiasi atau prosedur infasif pada pasien. Heart score merupakan predictor yang mudah, cepat dan tepat hasilnya, sesuai dengan pasien nyeri dada (Dai, 2018).

Heart score menilai langsung tanda klinis pasien yang datang dengan nyeri dada di Instalasi Gawat Darurat. Hearts score memiliki kelebihan dalam membedakan pasien sesuai klasifikasi. Heart score juga aman untuk diaplikasikan sehingga sangat direkomendasikan penggunan Heart score pada pasien nyeri dada di Instalasi Gawat Darurat (Poldervaart, 2017). 


\section{SIMPULAN}

Hasil yang didapatkan pada penerapan Heart score menunjukkan hasil interpretasi yang baik sesuai dengan klasifikasi pasien. Pasien yang memiliki nilai resiko rendah dapat dilakukan rawat jalan, pasien dengan resiko sedang mendapatkan monitoring dan pemeriksaan lebih lanjut, sedangkan pasien dengan resiko tinggi mendapatkan perawatan intensive serta dikonsultasikan dengan kardiologi. Penggunaan Heart score memberikan manfaat dalam membantu mengkalsifikasikan pasien berdasarkan resiko sehingga dapat membantu keputusan klinis yang tepat sesuai indikasi.

\section{SARAN}

Bagi tenaga medis khususnya perawat dan dokter yang bekerja di Instalasi Gawat Darurat dari hasil penerapan penggunaan heart score ini diharapkan dapat meningkatkan akurasi pengkajian pada pasien dengan nyeri dada yang tak terdefinisi. Nyeri dada yang teridentifikasi sejak dini dapat membantu dalam membuat keputusan klinis pada pasien sehingga dapat segera diberikan terapi sesuai dengan kondisi klinis pasien.

\section{DAFTAR PUSTAKA}

Amsterdam EA, Wenger NK, Brindis RG, Jr DEC, Ganiats TG, Jr DRH, et al. 2014. AHA / ACC Guideline for the Management of Patients With Non ST-Elevation Acute Coronary Syndromes. 344-426 p.

Bolvardi E, Raoufi P, Vakili V. 2016. Evaluation Efficacy of HEART Score in Prediction of Major Advanced Cardiac Events in Patients with Chest Pain Evaluation Efficacy of HEART Score in Prediction of Major Advanced Cardiac Events in Patients with Chest Pain.

Brady W, Souza K De. 2018. Turkish Journal of Emergency Medicine The HEART score: A guide to its application in the emergency department. Turkish J Emerg Med. Elsevier Ltd;18(2):47-51.

Dai S, Huang B, Zou Y, Guo J, Liu Z, Pi D, et al. 2018. The HEART score is useful to predict cardiovascular risks and reduces unnecessary cardiac imaging in low-risk patients with acute chest pain. :1-5.

Graham Grath. 2016. Acute Coronary Syndrome in women. Clinical Medical Insight Cardiology. 10: 1-10.

Hiestand BC, Mph MD. 2012. Can the HEART Score Safely Reduce Stress Testing and Cardiac Imaging in Patients at Low Risk for Acute Coronary Syndrome;10(3): 128-33.

Kemenkes. 2018. Riskesdas 2018. Jakarta: Pusdatin.

Khesroh Aliah Ali, Faizal Al-Roumi, Ibrahim Al-Zakwani, Sreeja Attur, Wafa Rashed, Mohammed Zubaid. 2017. Gender Difference among Patients with Acute Coronary Syndrome in the Midle East. Heart Views. 18(3): 77-82.

PERKI. 2018. Pedoman Tata Laksana Sindrom Koroner Akut. Jurnal Kardiologi 
Indonesia.

Poldervaart JM, Langedijk M, Backus BE, Dekker IMC, Six AJ, Doevendans PA, et al. 2017. Comparison of the GRACE , HEART and TIMI score to predict major adverse cardiac events in chest pain patients at the emergency department. Int J Cardiol. The Authors;227:656-61.

Pramadiaz AT, Fadil M, Mulyani H. 2014. Artikel Penelitian Hubungan Faktor Risiko Terhadap Kejadian Sindroma Koroner Akut pada Pasien Dewasa Muda di RSUP Dr . M . Djamil Padang;5(2):330-7.

Six AJ, Cullen L, Backus BE, Greenslade J, Parsonage W, Aldous S, et al. 2013. The HEART Score for the Assessment of Patients With Chest Pain in the Emergency Department A Multinational Validation Study;12(3):121-6.

Tomaszewski M, Topyła W, Kijewski BG, Miotła P, Waciński P. 2019. Review paper Does gender influence the outcome of ischemic heart disease;18(1):51-6.

WHO. 2018. Noncommunicable Diseases Country Profiles 2018. Geneva: WHO.

Zhou M, Liu J, Hao Y, Liu J, Huo Y, Jr SCS, et al. 2018. Prevalence and in hospital outcomes of diabetes among patients with acute coronary syndrome in China: findings from the Improving Care for Cardiovascular Disease in China Acute Coronary Syndrome Project. Cardiovasc Diabetol [Internet]. BioMed Central;(2):1-14. Available from: https://doi.org/10.1186/s12933-018-0793-x 